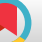

\title{
Duckett versus Modified Bracka Technique for Proximal Hypospadias Repair A 10-Year Experience
}

\author{
Afsaneh Sadeghi, ${ }^{1}$ Alireza Mirshemirani, ${ }^{2,}$ Ahmad Khaleghnejad Tabari, ${ }^{2}$ Naser Sadeghian, ${ }^{2}$ Mohsen \\ Rozroukh, ${ }^{2}$ Javad Ghoroubi, ${ }^{2}$ Leila Mohajerzadeh, ${ }^{2}$ and Mehdi Sarafi ${ }^{2}$ \\ ${ }^{1}$ Department of Pediatric Anesthesiology, Shahid Beheshti University of Medical Sciences, Tehran, IR Iran \\ ${ }^{2}$ Pediatric Surgery Research Center, Research Institute for Children Health, Shahid Beheshti University of Medical Sciences, Tehran, IR Iran \\ "Corresponding author: Professor Alireza Mirshemirani, Pediatric Surgery Research Center, Research Institute for Children Health, Shahid Beheshti University of Medical \\ Sciences, Tehran, IR Iran. Tel: +98-2122924488, E-mail: almirshemirani@gmail.com
}

Received 2016 October 25; Revised 2017 July 24; Accepted 2017 October 17.

\begin{abstract}
Background: There are various techniques for treatment of proximal hypospadias disease.Surgical correction is often associated with complications. Proximal hypospadias can be repaired by Duckett or Bracka two-stage repair procedure. This study was to evaluate the outcomes, complications and long term follow-up of these two techniques in our referral hospital.

Methods: From January 2006 to January 2015 totally 1550 cases of hypospadias were diagnosed in our hospital, of which 164 patients with high type hypospadias underwent Duckett (78 cases) and modified Bracka (86 cases) surgical repair procedures. Sufficient data were analyzed for age at operation, type of pathology, chordee type, number of operations, complications, outcomes and follow-up. Results: One hundred sixty four cases with a mean age of $2.70 \pm 2.6$ (range 0.5 - 13) years underwent proximal hypospadias repair. Follow up ran in average to 5 (range 1 - 10) years.Chordee was seen in $19(11.58 \%)$ cases which 15 (78.9\%) cases released and 4 (21.1\%) corrected by dorsal Nesbit plication. Fifteen of 164 (9.1\%) cases had meatal stenosis: 5 in Bracka and 10 in Duckett group, all of which were repaired by dilatation. Six patients in Duckett group and only one in Bracka series had urethrocutaneous fistula. One case in Bracka group and five cases in Duckett series underwent re-operation.

Conclusions: Our study shows that proximal hypospadias repair with modified Bracka procedure has significantly a lower complication rate, also a better and more cosmetic outcome than Duckett technique.
\end{abstract}

Keywords: Hypospadias, Modified Bracka Technique, Duckett Technique, Outcome, Children

\section{Background}

Hypospadias is the most common congenital anomaly of male external genitalia with an incidence rate of approximately 1 in 250 live male neonates born with proximal hypospadias. Proximal penile, penoscrotal and scrotal types account for $20 \%$ of all cases $(1,2)$. It is a significant surgical challenge to achieve a cosmetically and functionally acceptable straight penis in these patients. Surgical techniques for repairing proximal hypospadias generally have two categories: Free graft such as Bracka's two-stage procedure (3) and vascularized preputial island flap technique as Duckett's one-stage procedure (4). Each technique has its own advantages, but one-stage procedures are often associated with complications and require reoperations. Recent reports of one-stage repair state complication rates of $20 \%$ - 50\% (5-7), The debate over the optimal treatment for proximal hypospadias is ongoing, and mostly believe that two-stage procedure offers superior functional and cosmetic results with fewer complications (8) Bracka is a two-stage procedure: The first stage of Bracka repair consists of orthoplasty and urethral bed substitution with free preputial graft. After 6 months, the urethral plate created from free graft is tabularized to form neourethra. Twostage repairs reduce the complications and create better cosmetic view. In this study we compare outcomes of Duckett's one-stage technique with modified Bracka's two-stage procedure.

\section{Methods}

In a cross sectional study from January 2006 to January 2015 totally 1,550 cases of hypospadias were diagnosed in our hospital, of which 164 cases of severe proximal hypospadias with chordee and/or poor urethral plate underwent Duckett one-stage (78 cases) and modified Bracka 
two-stage (86 cases) surgical repair procedures. These procedures were performed by one group of surgeons in Mofid Children's University Hospital. All data was collected, retrospectively analyzed and variables were evaluated: Type of hypospadias, applied surgical technique, presence of chordee, releasing type, duration of catheterin place, type of dressing, duration of hospital stay, meatal stenosis, fistula development, need for re-operation, and outcomes were recorded. For statistical analysis SPSS version 18.0 and for descriptive statistics Chi-square and Student test were used. P 0.05 was considered as significant.

Surgical techniques: 1) Bracka is a two-stage procedure: The first stage of Bracka repair consists of orthoplasty and urethral bed substitution with free preputial graft (Figure 1). After 6 months, the urethral plate created from free graft is tabularized to form neourethra. In modified type of this technique that we have used, the graft is a vascularized preputial graft. 2) Duckett is a one-stage vascularized preputial island flap procedure.

\section{Results}

Within a period of 10 years, 164 patients aged $2.7 \pm 2.6$ (range 0.5 - 13) years, underwent proximal hypospadias repair, and were followed up for 5 (range 1 - 10) years(Table 1), Hypospadias repairs between January 2006 to January 2015 were performed in our center using Duckett (78 cases) and modified two-stage Bracka procedure (86 cases).From all patients. 72 had mid-penile hypospadias cases of which 38 were treated with Bracka and 34 with Duckett repair. Eighty four cases of proximal penile were treated either with Bracka (43patients) or Duckett (41 patients) repair and 8 patients had penoscrotal hypospadias of whom 5 cases were treated with Bracka and 3 patients with Duckett technique (Table 2).

Chordee was seen in 19 cases ( 9 mid penile, 6 proximal penile and 4 penoscrotal) of which 10 were released and 9 corrected by dorsal Nesbit plication. All patients had Foley silastic catheter in average.8 (range 5-8) days. Sandwich dressing was left in site for an average of $6.2(4-7)$ days. All patients received caudal block, antibiotics (Cephalosporin at least for 7 days) and post operative Oxybutynin. Fifteen of 164 (9.1\%) cases developed meatal stenosis: 10 (12.8\%) in Duckett and 5 (5.8\%) in Bracka group, these all were resolved by dilatation. Six (7.7\%) patients with Duckett repair had urethrocutaneous fistula, and only one (1.2\%) in Bracka group. Five cases (6.4\%) with Duckett group (one urethral diverticulum and four unsuccessful glans appearances) and one (1.2\%) with Bracka (glandular wound dehiscence) had redo operation. The hospital stay was longer in Duckett series (mean stay of 6.5 days for Duckett and 3.5 for Bracka group). Overall cosmetic result and complications were better in Bracka group compared with Duckett group (Table 3).

Table 1. Characteristics of the Patients with Hypospadias ${ }^{\mathrm{a}}$

\begin{tabular}{lc}
\hline Characteristics & Result \\
\hline Total patients & 164 \\
\hline Total duration of study, $\mathbf{y}$ & 10 \\
\hline Age & $2.7 \pm 2.6 \mathrm{y}(6 \mathrm{mo}-13 \mathrm{y})$ \\
\hline Proximal penile & $84(51.2)$ \\
\hline Penoscrotal & $8(4.9)$ \\
\hline Mid-penile & $72(43.9)$ \\
\hline Chordee & $19(11.6)$ \\
\hline \multicolumn{1}{|c}{ Mild } & $11(6.7)$ \\
\hline \multicolumn{1}{|c|}{ Moderate } & $3(1.8)$ \\
\hline \multicolumn{1}{|c|}{ Severe } & $5(3)$ \\
\hline Follow up, $y$ & $5 \pm 2.7(1-10)$ \\
\hline Fistulas & $7(4.3)$ \\
\hline Meatalstenosis & $15(9.1)$ \\
\hline Re-operation & $6(3.7)$ \\
\hline Values are & \\
\hline
\end{tabular}

${ }^{\mathrm{a}}$ Values are expressed as mean $\pm \mathrm{SD}$ or No. (\%).

Table 2. Surgical Procedure Type According to the Site of Hypospadias ${ }^{\mathrm{a}}$

\begin{tabular}{lccc}
\hline & Mid-Penile & Proximal Penile & Penoscrotal \\
\hline Bracka & $38(44.2)$ & $43(50)$ & $5(5.8)$ \\
Duckett & $34(43.6)$ & $41(52.6)$ & $3(3.8)$ \\
Total & $72(43.9)$ & $84(51.2)$ & $8(4.9)$ \\
\hline
\end{tabular}

${ }^{\mathrm{a}}$ Values are expressed as No. (\%).

\section{Discussion}

Surgical repair of proximal hypospadias still remains the greatest challenge, and it is important to select the correct technique to minimize complications and optimize the functional result and final appearance. Hypospadias repair is highly based on type and anomaly status, the surgeon's experience and technical selection $(9,10)$. The most common complications in hypospadias repair are fistula and meatal stenosis. The ultimate surgical goal is to achieve a normal or near normal appearance of penis, adequate meatal caliber, neourethra extending to the apex of glans for normal urine stream, and create a straight penis adequate for sexual intercourse $(11,12)$. 

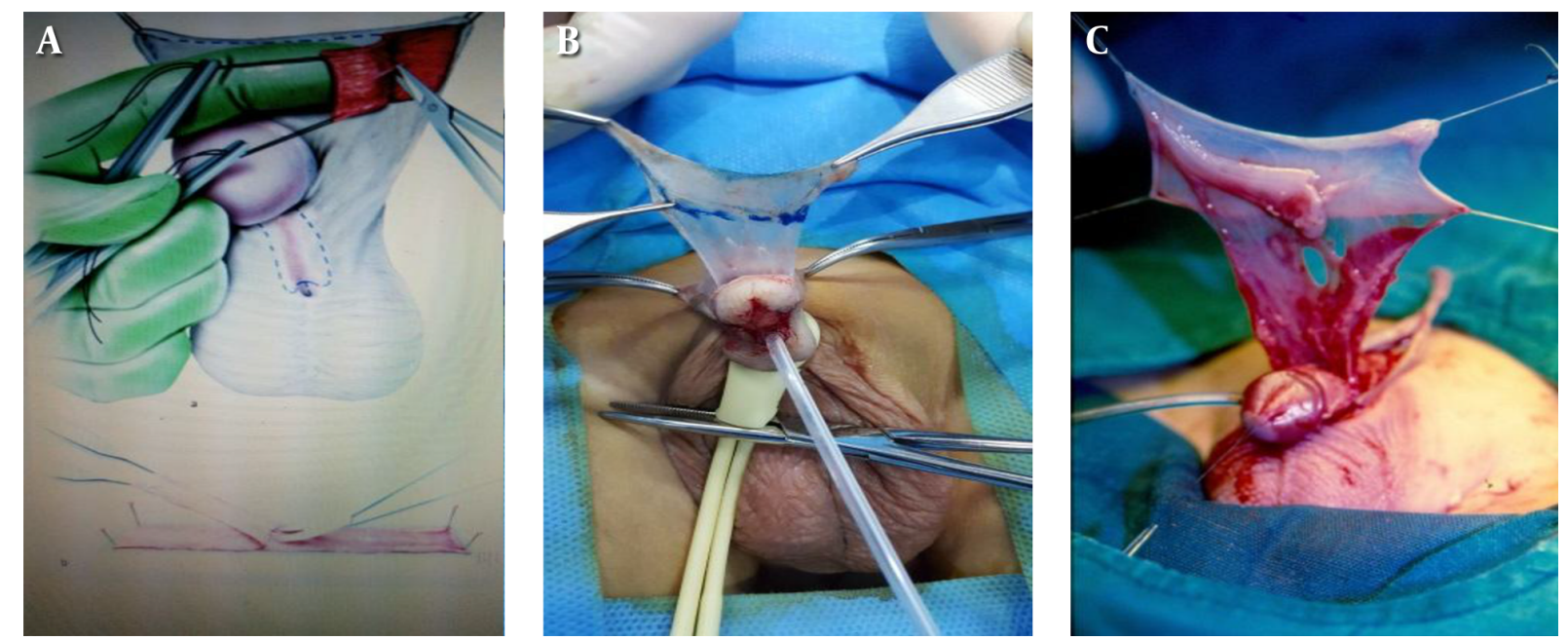

Figure 1. Free Graft in A, Two-Stage Bracka Technique; B, C, Vascularized Graft in Modified Bracka and Duckett Technique

Table 3. Overall Results in 164 Patients Based on Technique of Hypospadias Repair ${ }^{\mathrm{a}}$

\begin{tabular}{|c|c|c|c|c|}
\hline & Total & Bracka & Duckett & PValue \\
\hline Chordee & $19(11.6)$ & $11(12.8)$ & $8(10.3)$ & 0.635 \\
\hline Fistula & $7(3.8)$ & $1(1.2)$ & $6(7.7)$ & 0.054 \\
\hline Meatal stenosis & $15(9.1)$ & $5(5.8)$ & $10(12.8)$ & 0.175 \\
\hline Re-operation & $6(3.7)$ & $1(1.2)$ & $5(6.4)$ & 0.103 \\
\hline Complications & $28(17)$ & $7(8.1)$ & $21(26.9)$ & 0.0017 \\
\hline Mean hospital stay & $4.8 \pm 1.8$ & $3.5 \pm 1.1$ & $6.5 \pm 2.9$ & $<0.001$ \\
\hline
\end{tabular}

${ }^{\mathrm{a}}$ Values are expressed as No. (\%).

Contemporary series of single-stage repair report complication rates of $20 \%-50 \%(6,7)$. Generally surgical repair of proximal hypospadias is performed by two categories: Free graft as Bracka technique (3) and vascularized preputial island flap as Duckett procedure (4). Two-stage procedure usually offers better functional and cosmetic results with fewer complications (8). The Bracka two-stage repair is a choice procedure for severe hypospadias which create a full circumference urethral reconstruction and normal function with minimal complication $(9,13)$. Fathi et al. (11) report lower complications in Bracka technique than in Duckett procedure. Joshi et al. (9) report that twostage Bracka repair for severe proximal hypospadias with chordee and/or poor urethral plate is a good option with satisfactory results. Second layer in form of vascularized dartos or tunica vaginalis flap is perhaps mandatory to prevent fistula formation. Haxhirexha et al. (10) reported that overall complication rate of second stage was $8.3 \%$ (3 out of 36 patents) all of which occurred 6 months after surgery, fistula developed in two (5.5\%) patients that was repaired surgically, and one partial glans dehiscence was repaired with glansplasty. No meatal stenosis, urethral stricture, or diverticula formation were reported $(14,15)$. Current reports believe that a two-stage Bracka procedure is a very versatile technique which is being advised for all types of hypospadias. This technique creates normal appearance and function with minimal complications $(12,13,16,17)$. Cases with proximal hypospadias repair are at higher risk of complications compared with distal repairs. Review of literature notes that in one stage Duckett repair, fistula formation and meatal stenosis are higher than in two-stage techniques (18-20). Table 4 shows comparison of complications in three different studies.

\subsection{Conclusions}

Our study shows that in proximal hypospadias repair modified Bracka procedure creates a better outcome and 
Table 4. Comparison of Complications in Three Different Studies ${ }^{\mathrm{a}}$

\begin{tabular}{|c|c|c|c|c|}
\hline \multirow[t]{2}{*}{ Researcher } & \multicolumn{2}{|c|}{ Bracka } & \multicolumn{2}{|c|}{ Duckett } \\
\hline & Fistula & Meatal Stenosis & Fistula & Meatal Stenosis \\
\hline Fathi et al. (11): 21cases & 0 & $2(0.4)$ & $6(1.2)$ & $4(0.8)$ \\
\hline Joshi et al. (9): $\mathbf{4 3}$ cases & $1(0.2)$ & $1(0.2)$ & $2(0.5)$ & $1(0.2)$ \\
\hline Current study: 164 cases & $1(1.2)$ & $6(7.7)$ & $11(12.8)$ & $8(10.3)$ \\
\hline
\end{tabular}

${ }^{\mathrm{a}}$ Values are expressed as mean \pm SD or No. (\%).

minimal complication rate compared with Duckett technique.

\section{Acknowledgments}

We would like to thank Mrs Sayeh Hatefi for her kind help in preparing the references and submitting this manuscript.

\section{Footnote}

Funding/Support: This study was financially supported by the office of the vice chancellor for clinical research of Mofid Children's Hospital.

\section{References}

1. Baskin LS, Ebbers MB. Hypospadias: anatomy, etiology, and technique. J Pediatr Surg. 2006;41(3):463-72. doi: 10.1016/j.jpedsurg.2005.11.059. [PubMed: 16516617].

2. Duckett JW. Successful hypospadias repair. Contemp Urol. 1992;4(4):42-55.

3. Bracka A. A versatile two-stage hypospadias repair. Br J Plast Surg. 1995;48(6):345-52. [PubMed: 7551506].

4. Duckett JJ. Transverse preputial island flap technique for repair of severe hypospadias. 1980. J Urol. 2002;167(2 Pt 2):1179-82. [PubMed: 11905895] discussion 1183.

5. Glassberg KI, Hansbrough F, Horowitz M. The Koyanagi-Nonomura 1-stage bucket repair of severe hypospadias with and without penoscrotal transposition. J Urol. 1998;160(3 Pt 2):1104-7. [PubMed: 9719286] discussion 1137.

6. Demirbilek S, Kanmaz T, Aydin G, Yucesan S. Outcomes of one-stage techniques for proximal hypospadias repair. Urology. 2001;58(2):26770. [PubMed: 11489715].

7. Castanon M, Munoz E, Carrasco R, Rodo J, Morales L. Treatment of proximal hypospadias with a tubularized island flap urethroplasty and the onlay technique: a comparative study. J Pediatr Surg. 2000;35(10):1453-5. doi: 10.1053/jpsu.2000.16412. [PubMed:11051149].
8. Gershbaum MD, Stock JA, Hanna MK. A case for 2-stage repair of perineoscrotal hypospadias with severe chordee. J Urol. 2002;168(4 Pt 2):1727-8. doi: 10.1097/01.ju.0000027276.83141.8b. [PubMed: 12352345] discussion 1729.

9. Joshi RS, Bachani MK, Uttarwar AM, Ramji JI. The Bracka two-stage repair for severe proximal hypospadias: A single center experience. J Indian Assoc Pediatr Surg. 2015;20(2):72-6. doi: 10.4103/0971-9261.151549. [PubMed: 25829670].

10. Haxhirexha KN, Castagnetti M, Rigamonti W, Manzoni GA. Two-stage repair in hypospadias. Indian J Urol. 2008;24(2):226-32. [PubMed: 19468402].

11. Fathi K, Burger AE, Kulkarni MS, Mathur AB. Duckett versus Bracka technique for proximal hypospadias repair: A single centre experience. J Pediatr Surg Spec. 2008;2:11-3.

12. Johal NS, Nitkunan T, O'Malley K, Cuckow PM. The two-stage repair for severe primary hypospadias. Eur Urol. 2006;50(2):366-71. doi: 10.1016/j.eururo.2006.01.002. [PubMed:16464530].

13. Ramanathan C. Three-year experience of hypospadias surgery: Bracka's method. Indian J Plastic Surg. 2006;39(2):130. doi: 10.4103/0970-0358.29540.

14. Markiewicz MR, Lukose MA, Margarone J3, Barbagli G, Miller KS Chuang SK. The oral mucosa graft: a systematic review. J Urol 2007;178(2):387-94. doi: 10.1016/j.juro.2007.03.094. [PubMed: 17561150].

15. Mokhless IA, Kader MA, Fahmy N, Youssef M. The multistage use of buccal mucosa grafts for complex hypospadias: histological changes. J Urol. 2007;177(4):1496-9. doi: 10.1016/j.juro.2006.11.079. [PubMed: 17382762] discussion 1499-500.

16. Manzoni G, Bracka A, Palminteri E, Marrocco G. Hypospadias surgery: when, what and by whom? BJU Int. 2004;94(8):1188-95. doi: 10.1046/j.1464-410x.2004.05128.x. [PubMed: 15613162]

17. Gill NA, Hameed A. Management of hypospadias cripples with twostaged Bracka's technique.J Plast Reconstr Aesthet Surg. 2011;64(1):91-6. doi: 10.1016/j.bjps.2010.02.033. [PubMed: 20359973].

18. Khattak IU, Akbar M, Nawaz M, Al-Saleh A, Noor B, Zia ur R. An audit of single stage hypospadias repair at Ayub Hospital Complex, Abbottabad. J Ayub Med Coll Abbottabad. 2004;16(4):21-5. [PubMed: 15762057].

19. Elbakry A. Complications of the preputial island flap-tube urethroplasty. BJU Int. 1999;84(1):89-94. [PubMed: 10444131].

20. Bello A, Hussaini MY, Kura MM, Muhammed A, Tijjani LA. Hypospadias: 10 year review of outcome of treatment in pediatric urological practice. Sub-Saharan Afr J Med. 2015;2(1):28. 